\begin{tabular}{|c|c|} 
GEOAMBIENTE ON-LINE \\
Revista Eletrônica do Curso de Geografia - Campus Jatai- UFG \\
Graduaçäo e Pós-Graduaçäo em Geografia \\
www2.jatai.ufg.br/ojs/index.php/geoambiente \\
Apoio: PRPPG/PROAPUPEC \\
| Jataí-Go | n.13 | jul-dez/2009 |
\end{tabular}

\title{
ANÁLISE SÓCIO AMBIENTAIS DAS AGROINDÚSTRIAS FAMILIARES DO VALE \\ DO RIO DOS SINOS - RS
}

Roberto Harb Naime ${ }^{1}$, Sérgio Carvalho ${ }^{2}$

(1 - Centro Universitário Feevale, Doutor em engenharia ambiental, professor do curso de mestrado em qualidade ambiental, rnaime@feevale.br, 2 - coordenador do mestrado em qualidade ambiental, scarvalho@feevale.br)

\section{Resumo}

Este trabalho realiza uma interpretação dos aspectos sócio-ambientais das agroindústrias familiares do Vale do Rio dos Sinos. Foi realizada uma pesquisa junto as agroindústrias, sendo coletadas amostras de água e realizados ensaios microbiológicos. As principais agroindústrias desta região são de natureza alimentar, envolvendo frutas, legumes, hortaliças, grãos, oleaginosas, carne, leite e pescados. Apresentam níveis tecnológicos muito diferenciados. As agroindústrias familiares são grandes geradores de ocupação e renda. Aproveitam os excedentes de produção e buscam agregar valor aos produtos. Os principais impactos ambientais estão relacionados com o uso de água, contaminação de recursos hídricos e do meio físico em geral. A geração de resíduos e sobras é muito relevante, tanto no beneficiamento de vegetais quanto de carnes, com restos de ossos, sangue e tecidos que não tem destinação adequada. É apresentada a distribuição de agroindústrias pelos municípios constituintes do Vale do Rio dos Sinos, a faixa etária dos indivíduos que trabalham na produção, as fontes energéticas utilizadas e as fontes principais de recursos hídricos disponíveis. São feitas avaliações sobre a gestão dos resíduos sólidos produzidos que é muito reduzida e são feitas avaliações sobre os sistemas de tratamento de efluentes, que quando existentes são pobres e ineficientes. Finalizando são feitas avaliações microbiológicas da qualidade das águas utilizadas, indicando a presença de coliformes totais e fecais em grande parte das amostras de água analisadas, indicando que é urgente e necessária uma orientação aos responsáveis pelas agroindústrias para que venham a se enquadrar nos padrões de potabilidade exigidos pela portaria 518 do Ministério da Saúde.

Artigo recebido para publicação em 24 de Novembro de 2008;

Artigo aprovado para publicação em 05 de Setembro de 2009 


\begin{tabular}{|c|c|c|}
\hline & $\begin{array}{c}\text { GEOAMBIENTE ON-LINE } \\
\text { Revista Eletrônica do Curso de Geografia - Campus Jata } \\
\text { Graduação e Pós-Graduação em Geografia } \\
\text { www2.jatai.ufg.br/ojs/index.php/geoambiente } \\
\text { Apoio: PRPPG/PROAPUPEC } \\
\text { | Jataí-GO | n.13 | jul-dez/2009 | }\end{array}$ & $\begin{array}{l}\text { EEO } \\
\text { ISSN } 1679-9860 \\
\text { ISMBIENTE }\end{array}$ \\
\hline
\end{tabular}

Palavras-chave: aspectos sócio ambientais, caracterização, agroindústrias.

\section{Abstract \\ SOCIAL AND ENVIRONMENTAL ANALISYS OF FAMILY AGROINDUSTRIES OF RIO DOS SINOS VALLEY - RS}

This paper performs an interpretation of the social and environmental aspects of agricultural industries family of Vale do Rio dos Sinos. A search was conducted with the agricultural industries, and collected samples of water and conducted microbiological tests. The main agricultural industries of this region are likely food, involving fruits, legumes, vegetables, grains, oilseeds, meat, milk and fish. They present technological levels very differently. The family agricultural industries are major generators of employment and income. They utilize the excess production and searching for adding value to products. The main environmental impacts are related to the use of water, contamination of water resources and the physical mean in general. The generation of waste and surplus is very important, both in beneficiary eligibility of plants as meat, with remains of bones, blood and tissues that do not have proper destination. It is presented for the distribution of agricultural industries by municipalities constituents of Vale do Rio dos Sinos, the age range of individuals who work in production, the energy used and the main sources of water available. They are made assessments on the management of solid waste that is produced in very low assessments are made on the systems of treatment of effluents, which are poor when existing and inefficient. Finally assessments are made of the microbiological quality of water used, indicating the presence of total coliforms and fecal largely of water samples analyzed, indicating that it is urgent and necessary a guide to those responsible for agricultural industries to which they falls in the patterns of drinking required by Order 518 of the Ministry of Health.

Key words: social and environmental aspectos, characterization, agroindustries

\section{Resumen}

ANALISE AMBIENTAL Y SOCIOECONÓMICA DE LAS AGROINDUSTRIAS FAMILIARES DO VALE DO RIO DOS SINOS - RS 


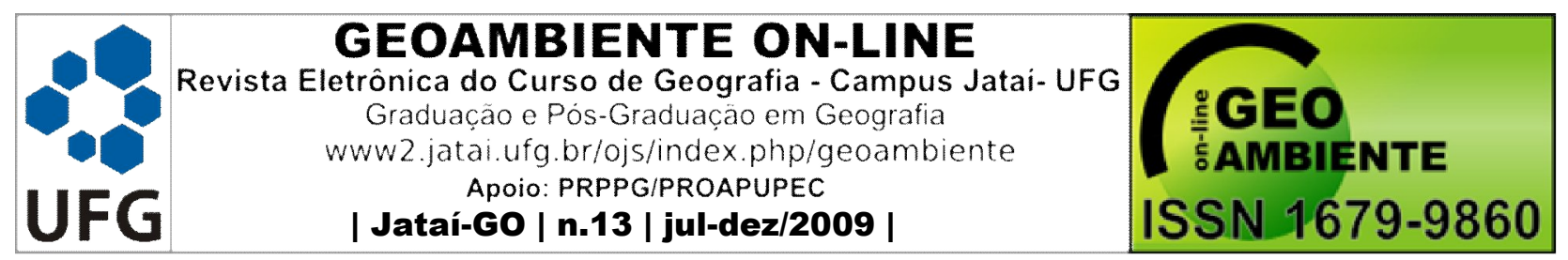

Este trabajo realiza una interpretación de los aspectos sociales y ambientales de la agroindustria de la familia de Río dos Sinos Valle. Se realizó una búsqueda con los agronegocios, y recogió muestras de agua y pruebas microbiológicas. Las principales industrias agrícolas en esta región son probablemente los alimentos, incluyendo frutas, legumbres, hortalizas, granos, semillas oleaginosas, carne, leche y pescado. Presentan niveles muy diferentes de la tecnología. Los generadores son grandes agronegocios familia de la ocupación y los ingresos. Aprovechar el excedente de producción y tratar de añadir valor a los productos. Los principales impactos ambientales están relacionados con el uso del agua, la contaminación de los recursos hídricos y el medio ambiente físico en general. La generación de residuos y la basura es muy importante, tanto en la mejora de plantas como la carne, con los restos de huesos, sangre y tejido que no es apropiado destino. Usted recibe la distribución de las industrias agrícolas mandantes por los municipios de Río dos Sinos Valley, el grupo de edad de las personas que participan en la producción, las fuentes de energía y las principales fuentes de los recursos hídricos disponibles. Las evaluaciones se realizan sobre la gestión de los residuos sólidos producidos es muy bajo y que las evaluaciones se realizan en el sistemas de tratamiento de efluentes, lo que si se dispone son pobres e ineficientes. Por último se realizan las evaluaciones de la calidad microbiológica del agua utilizada, lo que indica la presencia de coliformes totales y fecales en gran medida de las muestras de agua analizadas, lo que indica que es un urgente y necesario orientar a los responsables de los agronegocios a los que se encajan en los patrones de consumo de alcohol Ordenanza 518 exigidos por el Ministerio de Salud

Palabras clave: aspectos sociales e ambientales, caracterizacion, agroindustrias

\section{1 - Introdução}

As atividades agroindustriais são definidas como as atividades econômicas de industrialização ou beneficiamento de produtos agropecuários que geram valor agregado a estes produtos. A característica principal desta atividade é a conservação, transformação, enriquecimento ou conservação das matérias-primas agrícolas para destinação aos mercados.

As principais agroindústrias são de natureza alimentar, envolvendo frutas, legumes, hortaliças, grãos, oleaginosas, carne, leite e pescados. As agroindústrias apresentam níveis 


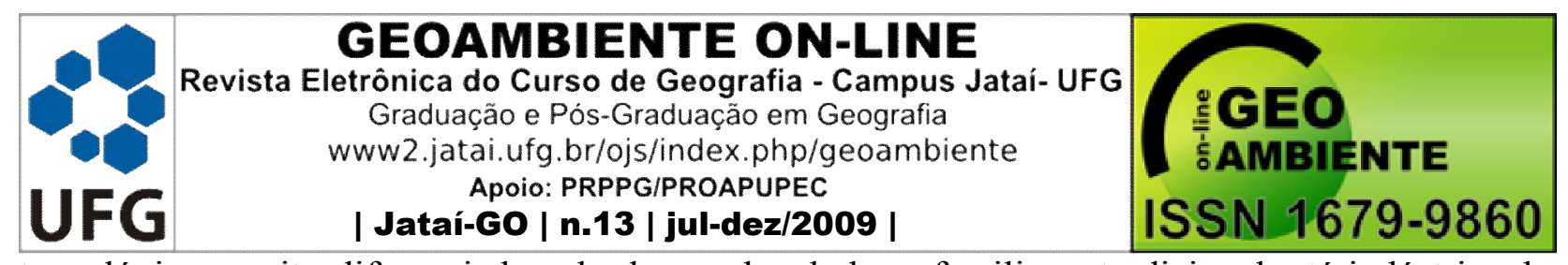

tecnológicos muito diferenciados, desde aquelas de base familiar e tradicional, até indústrias de ponta, com alta tecnologia e grande aparato tecnológico.

A agroindústria familiar é um segmento constituído por pequenos produtores rurais de alimentos de origem vegetal e animal (orgânicos ou não), além de massas e produtos de panificação. Esses produtores são, em geral, micro e pequenos empresários que ofertam produtos de baixa sofisticação tecnológica ligados à cultura local. A transformação desses produtos ocorre de forma artesanal e informal, em pequenas instalações. Em sua grande maioria trata-se de produtos com processamento simples, com baixo conteúdo tecnológico, mas que apresentam um potencial de agregação de valor significativo.

Em geral, as atividades de agroindústria familiar são importantes empregadoras de mãode-obra não qualificada e servem para valorizar o trabalho doméstico. Além disso as agroindústrias familiares promovem o envolvimento de jovens rurais, permitindo-lhes assim permanecerem no campo, aumentando suas rendas bem como de suas famílias.

Os grupos de pequenas e micro-agroindústrias não são homogêneos e são compostos por representantes que atuam na área rural. A agroindústria familiar rural, em geral, se constitui a partir de duas motivações comuns. A primeira (mais freqüente) é o aproveitamento de excedentes que o produtor não consegue vender, seja por não atender aos padrões de comercialização ou por não atender aos requisitos de qualidade exigidos pelo mercado. A segunda motivação surge em períodos de conjunturas desfavoráveis de preço para a produção agrícola, levando o produtor a optar pela agroindustrialização como uma forma de agregar valor aos seus produtos.

No Rio Grande do Sul, os estabelecimentos rurais de base familiar ocupam em torno de $41 \%$ da área rural total, contribuem com 58\% do valor bruto da produção e com 11\% do PIB gaúcho, o que caracteriza a importância deste segmento da sociedade. No Vale do Rio dos Sinos, as propriedades existentes caracterizam-se por minifúndios, pequenas e médias propriedades, na maioria de origem familiar, sendo que na busca de um melhor desenvolvimento do setor, atividades agroindustriais tem sido desenvolvidas.

Contudo, pelas carências na análise global de aspectos de infra-estrutura ligados à industrialização, fato típico e característico das agroindústrias familiares, fatores como água, energia, tratamento e lançamento de efluentes e disposição de resíduos sólidos, que são críticos em processos industriais, freqüentemente são negligenciados. Este fato gera impactos ambientais 


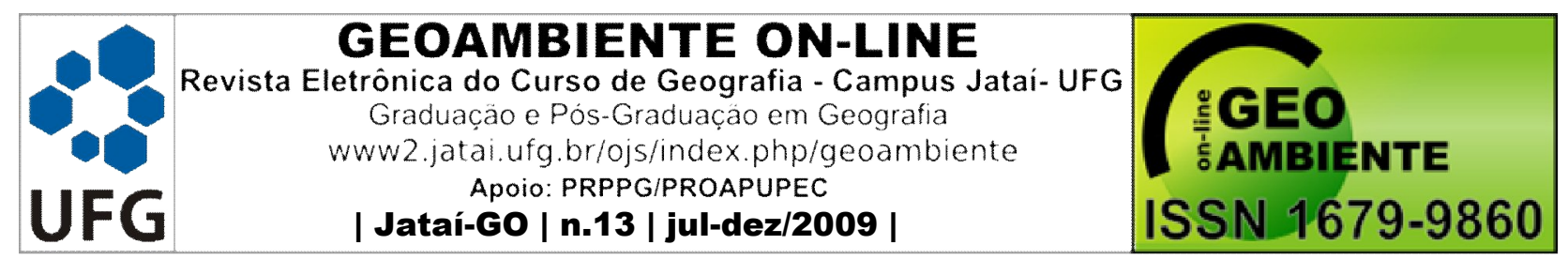

relevantes no meio ambiente, que nem sempre tem condições de suporte natural para absorver as incidências causadas.

Os cuidados com o manuseio, preparação, processamento e armazenamento das matériasprimas beneficiadas e transformadas deveriam sofrer cuidadoso processo de planejamento, em geral ausente nas agroindústrias, pelas deficiências de formação dos recursos humanos e dificuldades de capital existentes (NAIME, 2005). Este fato se torna mais relevante, considerando que a maior parte dos materiais a serem beneficiados ou conservados tem alto índice de degradabilidade e demandam por cuidados sanitários especiais (SANTOS e CERQUEIRA, 2007).

Os principais impactos estão relacionados com o uso da água, contaminação dos recursos hídricos (NASCIMENTO et al, 2007) e do meio físico em geral, e problemas derivados das águas servidas (pias, chuveiros e sanitários), cuja única destinação adequada é o lançamento na rede pública de coleta de esgotos para tratamento, que geralmente não existe na área rural ou semirural (BANCO DO NORDESTE, 1999, BRASIL, 1981).

A contaminação das águas varia de acordo com a vazão dos efluentes produzidos, que são gerados nas operações de lavagem, enxaguamento, transporte interno das matérias-primas e limpeza do ambiente de trabalho e dos equipamentos de processamento.

Efluentes em geral possuem alto nível de demanda bioquímica e química de oxigênio, conhecidos como DBO e DQO, apresentando ainda elevados teores de sólidos suspensos e dissolvidos, a presença de óleos e graxas e ainda infectantes microbiológicos, como colibacilos (RICHTER e NETTO, 1995).

Dependendo da natureza dos insumos utilizados, podem estar presentes resíduos de agrotóxicos, óleos complexos, compostos alcalinos e outras substâncias orgânicas diversas, que muitas vezes podem dificultar qualquer tratamento ou destinação para os efluentes, tornando onerosas as operações.

A geração de sobras e resíduos de processamento também é muito relevante tanto no beneficiamento de vegetais quanto de carnes, com restos de ossos, sangue e tecidos que não tem destinação adequada. Este item merece cuidadoso levantamento e planejamento para que não produza passivos ambientais incontornáveis dentro da realidade sócio-econômica das agroindústrias, principalmente familiares, artesanais ou de pequeno-porte. 


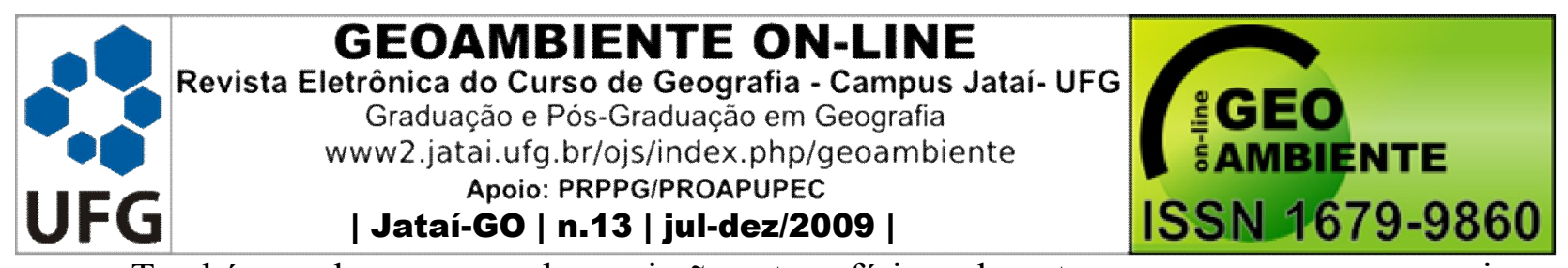

Também podem ser geradas emissões atmosféricas durante os processos, como poeiras, materiais particulados, materiais pulverizados, dióxido de enxofre, óxidos nitrosos, derivados de hidrocarbonetos e outros compostos orgânicos.

Outros itens vinculados às concepções de desenvolvimento sustentável, como otimização do uso de recursos hídricos e determinação de eficiência energética, assim como compromissos comunitários e sociais, geralmente nem são avaliados em empreendimentos agroindustriais, principalmente de natureza familiar ou artesanal.

Neste trabalho foram estudados os principais tipos de processamentos agroindustriais familiares desenvolvidos na Região do Vale do Rio dos Sinos, visando caracterizar a atividade e os impactos ambientais potenciais.

\section{2 - Materiais e métodos}

Foram aplicados questionários ao público interno das agroindústrias, constituído pelos funcionários visando o conhecimento sobre o tema. A pesquisa qualitativa foi escolhida, por que de acordo com GOEBERT (2003, p.60): “as pesquisas qualitativas estimulam a revelar os processos de pensamento e detectam sua relação emocional”. Além disso, as emoções são por definição "inconscientes”, conforme assevera ZALTMAN (2003) e podem revelar as melhores estratégias para sensibilização, tomando por base a situação real e não abstrações hipotéticas contaminadas pela visão do executor.

MARGENEU e BERGAMINI (1982) afirmam que a pesquisa qualitativa é tão válida quanto à quantitativa, que era considerada a verdadeira pesquisa científica. Para estes autores, cada uma deve ser utilizada conforme a natureza do fenômeno a ser estudado, levando em consideração sua adequabilidade ao problema.

A partir deste enfoque, se considera que através de um estudo exploratório qualitativo e parcialmente quantitativo, utilizando como instrumento pesquisa em profundidade, a interpretação dos dados torna possível a obtenção de subsídios adequados para planejamento e ações futuras. Este procedimento é mais justificado ainda pelo fato de não existirem pesquisas ou outras abordagens que pudessem orientar estes trabalhos.

Os estudos exploratórios são feitos, normalmente, quando o objetivo da pesquisa é examinar um tema ou problema de investigação pouco estudado ou que não tenha sido abordado 


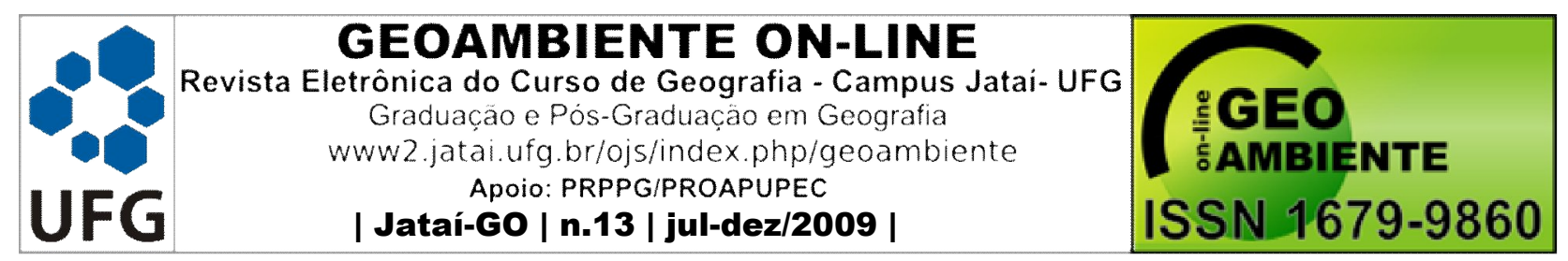

antes. Dentro desta concepção optou-se por uma pesquisa qualitativa, tanto pelas dificuldades de realização de pesquisa quantitativa, como pelo fato de que pesquisas qualitativas, "baseadas em pequenas amostras, proporcionarem insight e compreensão do contexto do problema. Foram aplicados 90 questionários. (MALHOTRA, 2001, p.155). Este mesmo autor destaca que o caráter qualitativo é "desestruturado e de natureza exploratória, baseada em amostras pequenas e pode utilizar técnicas qualitativas conhecidas como grupos de foco, associação de palavras e outros".

Também se consideram que uma pesquisa quantitativa muitas vezes usadas em ciências sociais (ROSSI e HOR MYELL, 2001) são apropriadas para capturar visões do mundo social como estruturas concretas, mas nem sempre são eficientes quando aspectos de comportamento pessoal se misturam com o objeto da pesquisa.

As emoções estão intimamente ligadas ao inconsciente humano e muitas vezes "existem pensamentos ocultos e idéias que talvez não sejam explícitas", mas que é fundamental para os objetivos de obter eficiência e eficácia na futura implantação de sistemas globais de gestão ambiental, partindo da gestão de resíduos sólidos, aspecto mais crítico e visível da situação.

A pesquisa qualitativa é capaz de captar com maior precisão, os procedimentos adotados e as motivações conscientes ou inconscientes do mesmo e ajudar a definir o problema (BRASIL, 2004)

A pesquisa foi executada tendo por ponto de partida os procedimentos atualmente realizados e as legislações anteriores e atuais. A partir desta compreensão, foi procedida a elaboração de questionários para entrevistas em profundidade (FLICK, 2004).

A entrevista em profundidade é uma "técnica de entrevista pouco estruturada, conduzida por um moderador experiente, com um único entrevistado de cada vez para obtenção de dados sobre determinado assunto focalizado".

MALHORTA (2001, p.163) descreve a entrevista em profundidade como "uma entrevista não-estruturada, direta, pessoal, em que um único respondente é testado por um entrevistador altamente treinado, para descobrir motivações, crenças, atitudes e sensações subjacentes sobre um tópico" e tem como uma das suas aplicações a compreensão de um comportamento detalhado.

A tecnologia de pesquisas é mais utilizada em marketing e nas ciências sociais, mas a apropriação destes conceitos por outras áreas do conhecimento é válida e necessária, pois esta é 


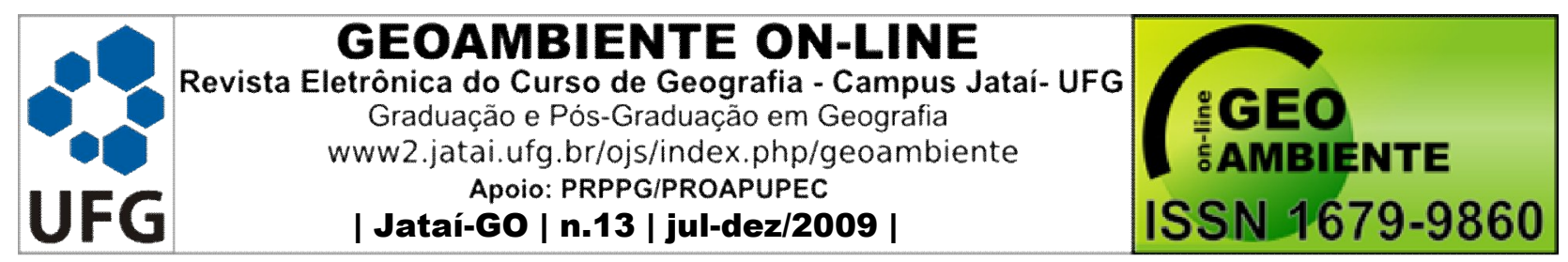

uma técnica dedutiva que opera sobre a realidade real e partindo do diagnóstico desta situação, propõe soluções adequadas.

Segundo vários autores (ANASTACI e URBINA 2000; e TRIVIÑOS 1992) os entrevistados tendem a se sentir mais confortáveis as questões formuladas quando expostos individualmente, do que numa situação de grupo focal, onde necessitariam se expor diante dos outros. Também é reconhecido que "pesquisas em profundidade são uma das fontes mais utilizadas em pesquisa qualitativa, pois, através do discurso dos depoentes é possível acessar parcela representativa da forma como pensam e percebem a realidade".

Alguns autores consideram a entrevista como instrumento por excelência da investigação social (LAKATOS e MARCONI, 1999). Mas a possibilidade de avaliar de forma flexível às atitudes, condutas, percepções e a observação do comportamento dos entrevistados possibilitam a montagem de quadros de extrema realidade, que não podem ser negligenciados.

Será utilizado roteiro semi-estruturado, com questões opinativas para enriquecimento das percepções a serem obtidas com a pesquisa por setor e a destinação atualmente conferida para os resíduos, com uma projeção dos procedimentos e aspectos legais que induzem ao aprimoramento. (BARBIERI, 2004).

As técnicas projetivas (BARDIN 1977 e ANASTASI e URBINA 2000) são muito adequadas para revelar aspectos de personalidade associados aos procedimentos e permitir o enriquecimento dos dados e melhor planejamento das ações subseqüentes.

O período de aplicação da pesquisa foi de fevereiro de 2006 até fevereiro de 2007. Deste momento em diante foram realizadas interpretações detalhadas dos resultados, tanto objetivos quanto subjetivos detectados e expostos em diagramas e interpretações compreensivas.

O questionário aborda os principais indicadores sócio-econômicos e ambientais, sendo eles: de renda, incorporando renda familiar total; de mercado de trabalho, incorporando pessoas empregadas e desempregadas; educacionais, incorporando escolaridade média, e acesso de bens à informação e cultura; e de localização, incorporando a proximidade da propriedade à sede do município.

Também foram investigadas as condições das instalações, equipamentos, matéria-prima, produtos produzidos e locais de comercialização, quesitos exclusivos da agroindústria. O 


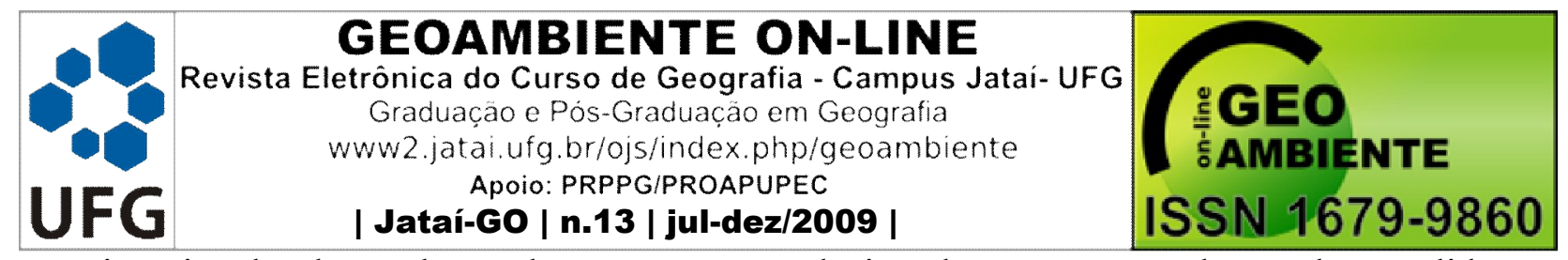

questionário aborda também alguns aspectos relacionados a geração de resíduos sólidos e líquidos durante os processos agroindustriais, bem como as formas de tratamento destes resíduos.

Os elementos estudados neste trabalho foram selecionados baseados em seu potencial de toxicidade para o homem e por serem utilizados nas indústrias desta região. Para as determinações dos parâmetros de DBO, dureza, alcalinidade, cloretos, nitrogênio amoniacal, fósforo total, ferro, alumínio, zinco, sólidos dissolvidos totais, $\mathrm{pH}$ e nitratos. Foram coletadas amostras em frascos com capacidade de um litro, previamente preparados para este fim.

As determinações físico-químicas foram realizadas em duplicata pela Central Analítica do Centro Universitário Feevale, tendo como base de referência o Standard Methods for Examination of Water and Wastewater, $21^{\text {th }}$ Ed, 2005. Foram realizadas ainda análises microbiológicas de coliformes totais e coliformes fecais nas amostras coletadas.

\section{3 - Resultados e discussão}

A abordagem do estudo realizado inicia pela avaliação do porte da agroindústria se é familiar ou empresarial. O objetivo do estudo são as agroindústrias familiares. Depois classifica quanto a tipologia: animal, vegetal ou sucos e bebidas. A seguir avaliou-se a situação legal da atividade, se formal ou informal. Finalizando é feita uma análise da legalização. Uma agroindústria deve estar legalizada e deve ter registro nos Sistemas de Inspeção, Federal, Estadual, Municipal, Vigilância Sanitária e IBAMA

$\mathrm{O}$ estudo tem como objeto as agroindústrias familiares do Vale do Rio dos Sinos. A distribuição dos empreendimentos estudados por município é apresentada na Figura 1 a seguir.

A pesquisa realizada buscou identificar se havia uma predominância de faixa etária entre os envolvidos com as agroindústrias familiares. Os resultados se encontram apresentados na Figura 2. 


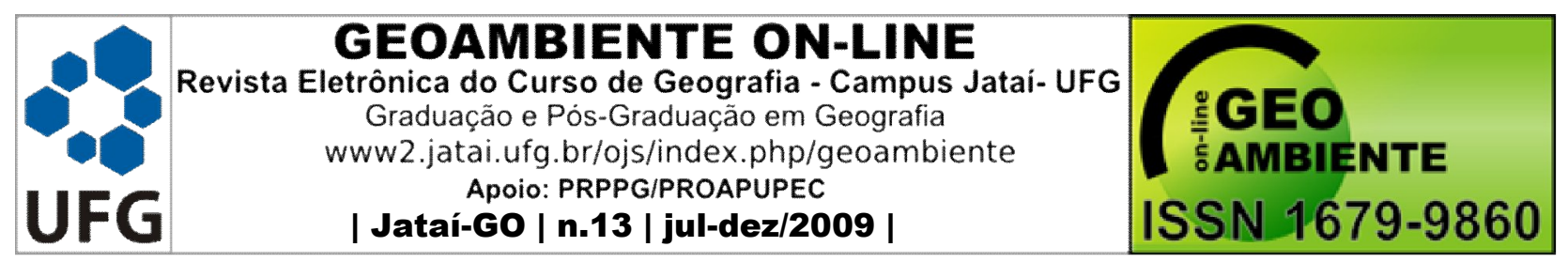

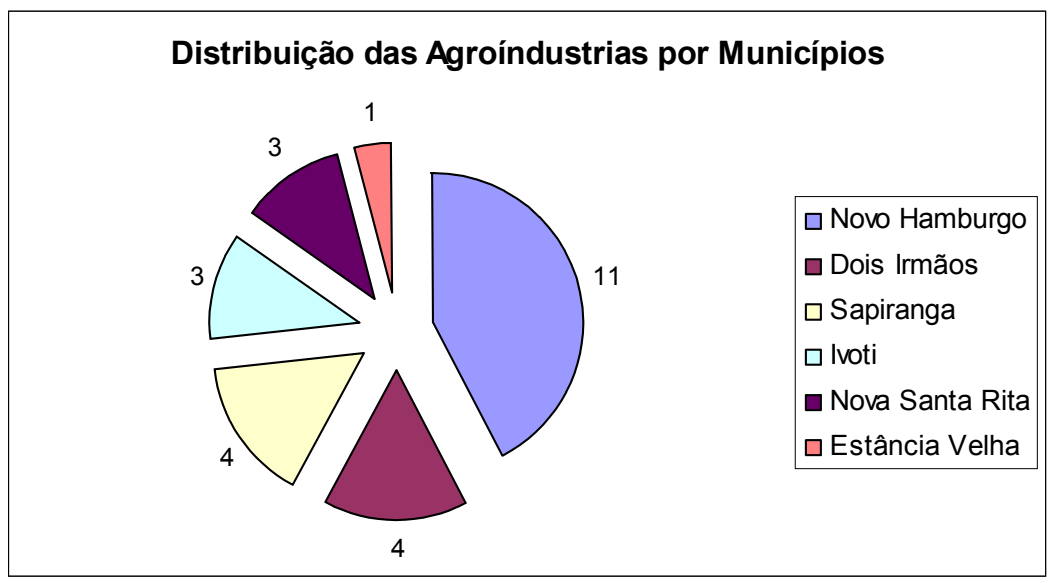

Figura 1: Distribuição das agroindústrias por município do Vale do Rio dos Sinos em quantidade numérica.

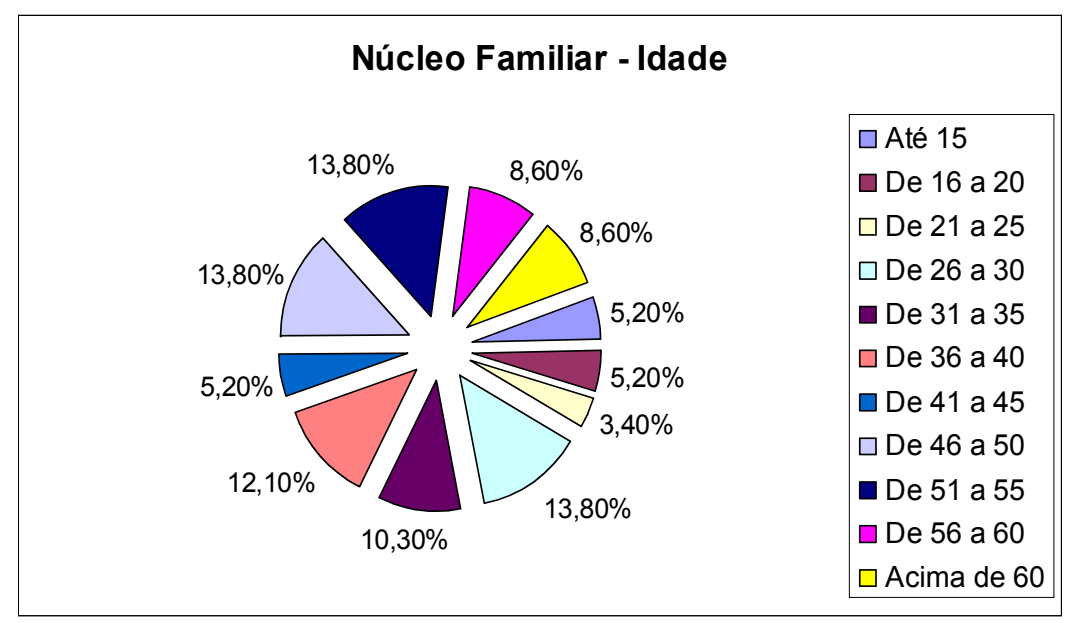

Figura 2: Distribuição ocupacional por faixa etária.

Na figura acima é possível observar que mais de $60 \%$ dos envolvidos tem idades acima de 36 anos, o que permite caracterizar as agroindústrias familiares do Vale do Rio dos Sinos como uma importante fonte de ocupação e renda para a faixa etária mais madura e até da terceira idade. Estes indivíduos são os que encontram maiores dificuldades para se colocarem ou recolocarem nos mercados formais ou até mesmo informais de trabalho. 


\begin{tabular}{|c|c|} 
GEOAMBIENTE ON-LINE \\
Revista Eletrônica do Curso de Geografia - Campus Jatai- UFG \\
Graduação e Pós-Graduação em Geografia \\
www2.jatai.ufg.br/ojs/index.php/geoambiente \\
Apoio: PRPPG/PROAPUPEC \\
| Jataí-Go | n.13 | jul-dez/2009 |
\end{tabular}

Do total do universo pesquisado, quase $18 \%$ dos envolvidos tem idade superiores a 56 anos, o que torna esta atividade de profundo interesse social para todas as comunidades envolvidas.

A principal fonte de energia para as agroindústrias é elétrica. $\mathrm{O}$ quadro 1 mostra os resultados encontrados.

Quadro 1: Fontes energéticas das agroindústrias familiares.

\begin{tabular}{|l|c|c|}
\hline \multicolumn{1}{|c|}{ Fonte Energética } & Citações & Frequência \\
\hline Energia elétrica & 24 & $92,32 \%$ \\
\hline Elétrica e Biogás & 1 & $3,84 \%$ \\
\hline Elétrica e Engenho com trator & 1 & $3,84 \%$ \\
\hline Total & $\mathbf{2 6}$ & $\mathbf{1 0 0 , 0 0 \%}$ \\
\hline
\end{tabular}

Este quadro demonstra a importância da eletrificação rural na melhoria da qualidade de vida das populações rurais. As agroindústrias permitem geração de emprego e renda, agregam valor na produção primária e se viabilizam somente com os recursos da eletrificação rural. Complementando a importante informação, foi pesquisado o tipo de energia elétrica disponível e os resultados estão apresentados no Quadro 2.

Quadro 2: Tipo de energia elétrica utilizada.

\begin{tabular}{|l|c|c|}
\hline \multicolumn{1}{|c|}{ Tipo de energia elétrica } & Quantidade citada & Frequência \\
\hline Trifásica & 14 & $53,92 \%$ \\
\hline Monofásica & 12 & $46,08 \%$ \\
\hline Total & $\mathbf{2 6}$ & $\mathbf{1 0 0 , 0 0} \%$ \\
\hline
\end{tabular}

A maior parte das agroindústrias tem instalação elétrica trifásica (14) e a outra parte (12) apresentam instalação elétrica monofásica. Por este dado é possível afirmar que a maioria quando solicitou instalação elétrica tinha ou pretendia ter e operar equipamentos elétricos de potência elevada.

Outro dado muito relevante na investigação sócio-ambiental das agroindústrias familiares é a fonte de recurso hídrico que utilizam. A água é fundamental para os processos agroindustriais e para a higienização das instalações. Manter a qualidade dos recursos hídricos significa manter as melhores condições sanitárias nos empreendimentos (AZEVEDO e NETTO, 1991). 


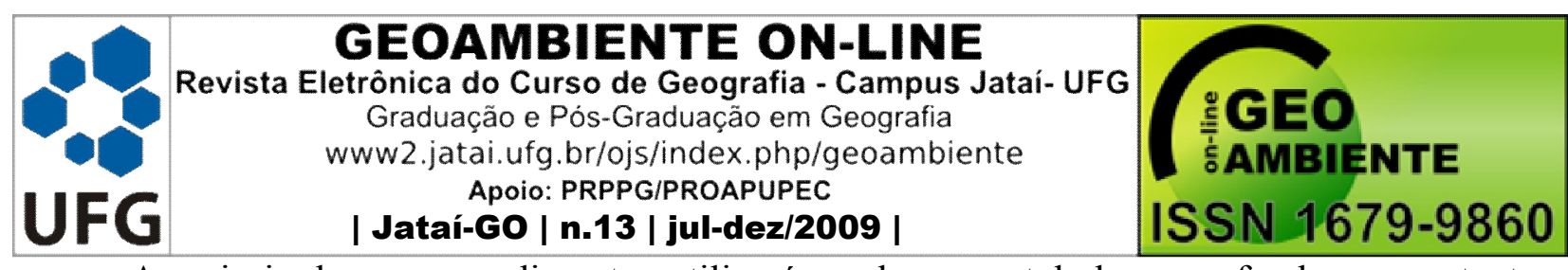

A maioria dos empreendimentos utiliza água de poços tubulares profundos ou vertentes.

Poços rasos que utilizam água dos lençóis freáticos e das nascentes.

Existe pouca distinção entre vertentes ou nascentes, que se tratam de situações muito parecidas. Em 5 estabelecimentos foi citado o abastecimento público. Na Figura 3 a seguir são apresentados os resultados.

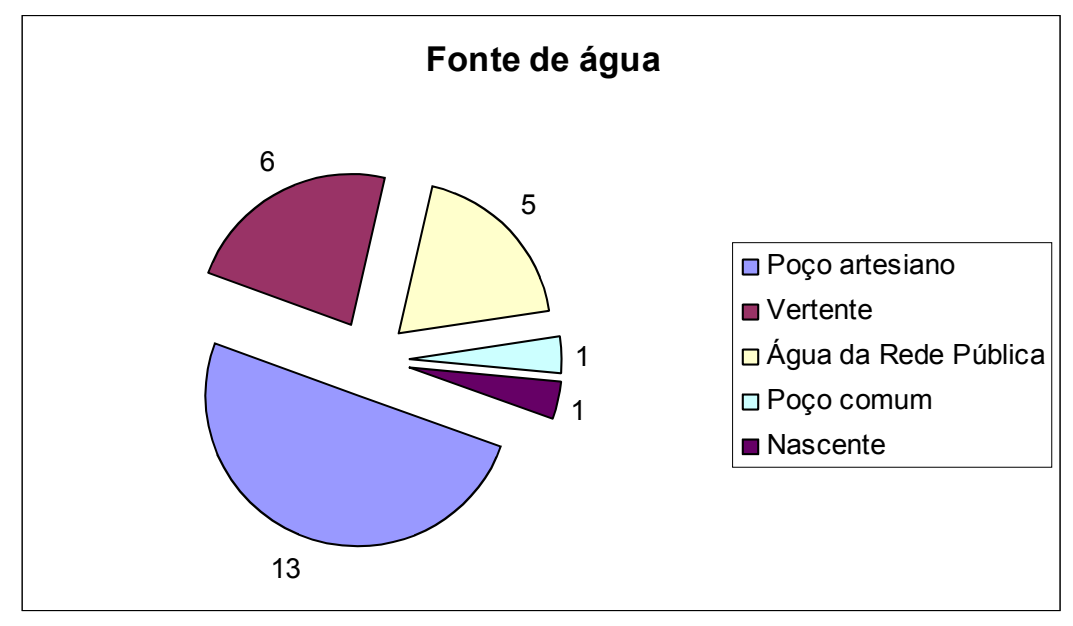

Figura 3: Fontes de recursos hídricos citadas.

Seguindo a investigação sobre recursos hídricos, foram avaliadas quantas propriedades tem tratamento de água. Os resultados estão na Figura 4 a seguir.

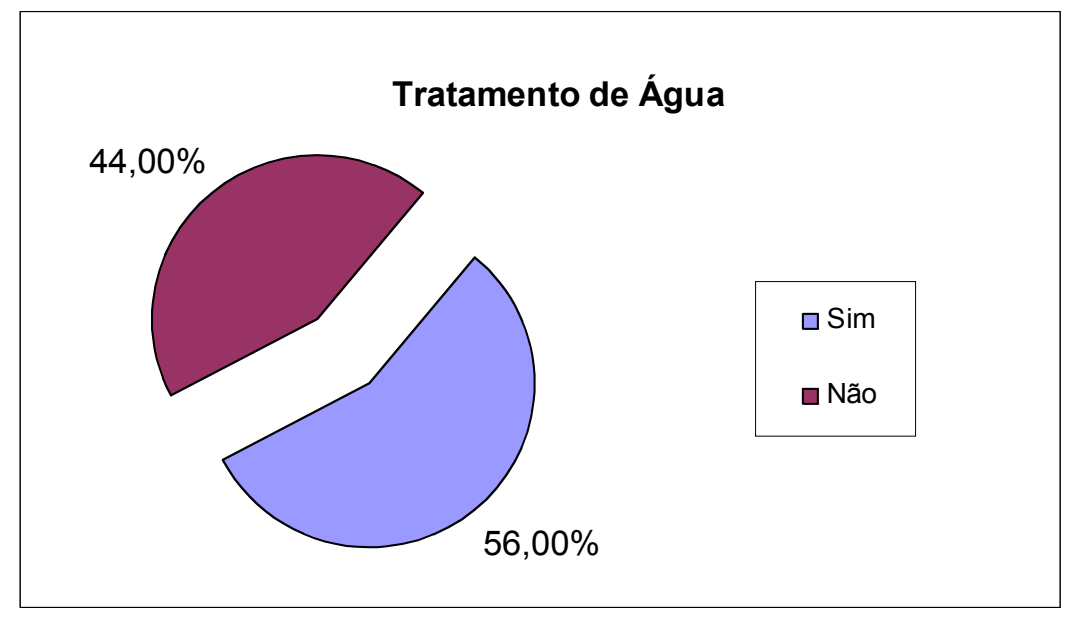

Figura 4: Agroindústrias familiares que dispõem de tratamento de água. 


\begin{tabular}{|c|c|c|}
\hline UFG & $\begin{array}{c}\text { GEOAMBIENTE ON-LINE } \\
\text { Revista Eletrônica do Curso de Geografia - Campus Jatai } \\
\text { Graduacăao e Pós.-Graduação em Geografia } \\
\text { www2.jatai. ufg.br/ojs/index.php/geoambiente } \\
\text { Apoio: PRPPG/PROAPUPEC } \\
\text { Jataí-GO | n.13 jul-dez/2009 }\end{array}$ & $\begin{array}{l}\text { ĖGEO } \\
\text { ISSN } 1679-9860\end{array}$ \\
\hline
\end{tabular}

Um dos maiores problemas identificados nas agroindústrias é a gestão dos resíduos sólidos produzidos.

Ossadas podem ser dirigidas a fábricas de rações de farinha de osso, se constituindo em grandes fontes de carbonatos de cálcio e magnésio. Mas a falta de orientação e muitas vezes a falta de infra-estrutura adequada, muitas vezes fazem com que ocorram descartes clandestinos e irregulares dos resíduos sólidos de qualquer natureza que sejam produzidos.

Resíduos sólidos de natureza agroindustrial são em sua maioria biodegradáveis, resultantes de restos vegetais ou animais, mas em ambos os casos necessitam destinação adequada e processos de compostagem ou tratamento adequados.

Os indivíduos envolvidos com atividades nas agroindústrias familiares do Vale do Rio dos Sinos, como na maioria das agroindústrias do país, desconhece os princípios básicos de gestão de resíduos sólidos, que podem ser resumidos nos seguintes itens:

$>$ menor produção possível de resíduos,

$>$ reutilização ou reciclagem dos mesmo,

$>$ segregação na origem,

$>$ acondicionamento e transporte internos adequados,

$>$ tratamento, acondicionamento e transporte externo em condições sanitárias adequadas.

O manejo dos resíduos sólidos deve estar em conformidade com as boas práticas necessárias para a fabricação de produtos agroindustriais e respeitando as condições específicas normatizadas pelas legislações vigentes, tanto Resoluções do Conselho Nacional do Meio Ambiente (CONAMA) quanto dos demais órgãos de controle ambiental estaduais ou até mesmo municipais.

As destinações de resíduos mais citadas foram a adubação e a alimentação de animais. A seguir vem a disposição inadequada a céu aberto e processos de compostagem, cama para suínos, fábrica de rações ou aterramento. Em um caso foi citada a queima simples dos resíduos e em outro a destinação para aterros sanitários públicos, ou mais especificamente para lixões de administração pública dos municípios. 


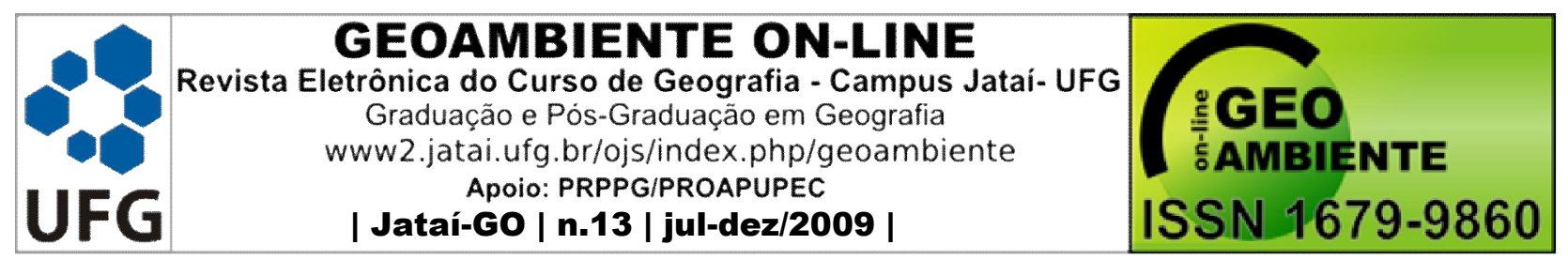

Quase todas as agroindústrias pesquisadas no âmbito do projeto envolvendo a região hidrológica da Bacia do Bale do Rio dos Sinos produzem algum tipo de resíduo, o mais comum são ossadas de descarte de animais (Figura 5).

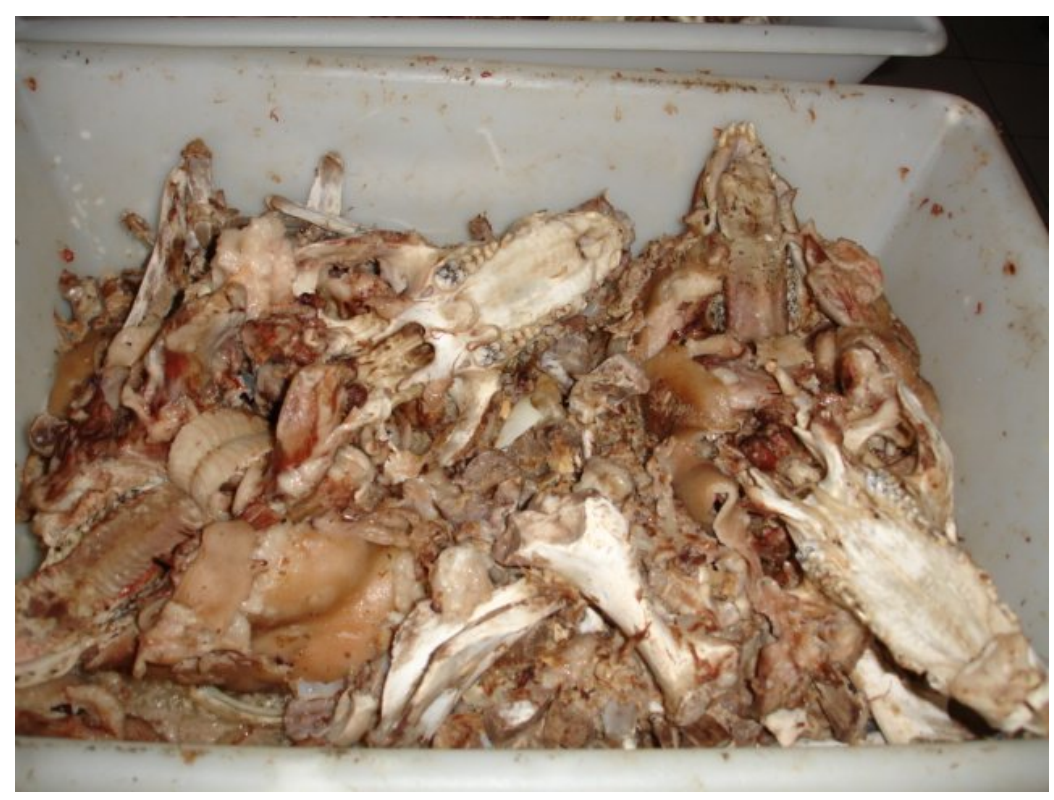

Figura 5: Resíduos sólidos de ossadas, produzido em agroindústrias familiares.

$\mathrm{Na}$ Figura 6, são identificados os principais tipos de resíduos produzidos nas agroindústrias pesquisadas.

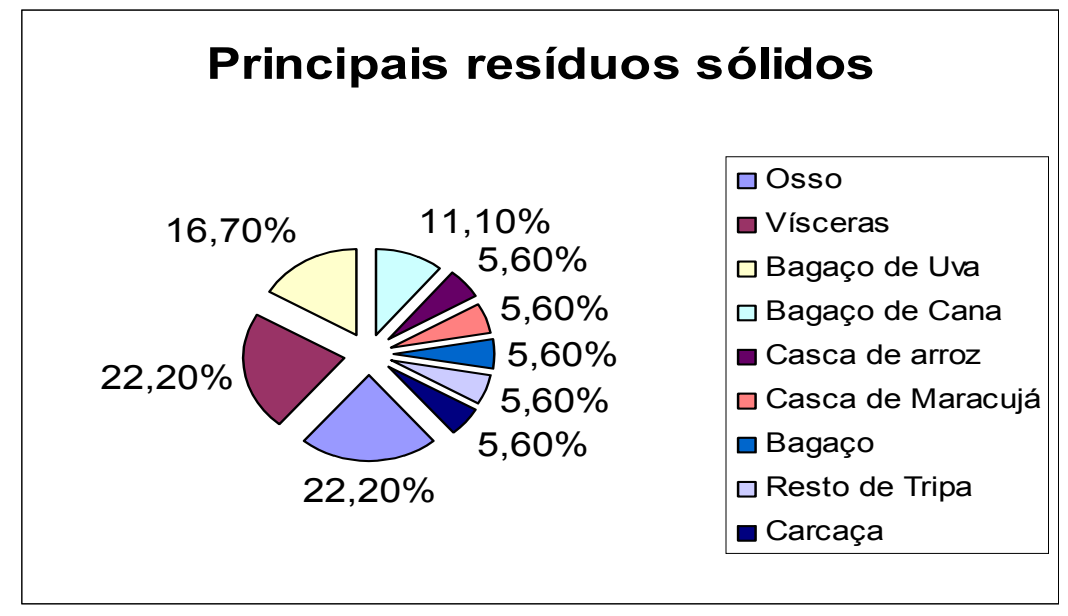

Figura 6: Natureza dos principais tipos de resíduos sólidos produzidos. 


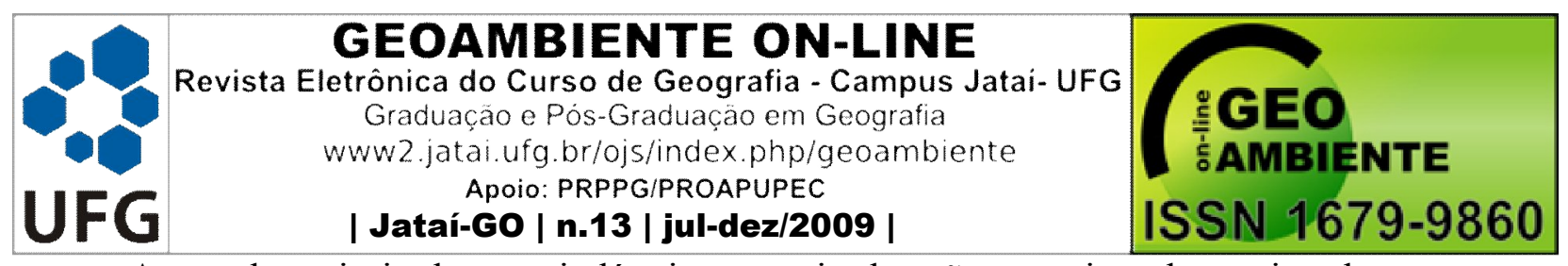

A grande maioria das agroindústrias pesquisadas não possui qualquer tipo de tratamento para os resíduos sólidos que produz.

E as destinações finais que são citadas não estão em conformidade com as boas práticas de fabricação e freqüentemente em desacordo com as normas e regulamentos vigentes, que são desconhecidos da maioria dos atores encontrados nas agroindústrias pesquisadas no Vale do Rio dos Sinos.

$\mathrm{Na}$ avaliação seguinte, os principais processos hidrológicos aplicados (TUCCI, 1993) começam a ser investigados dentro do contexto das agroindústrias familiares pesquisadas no Vale do Rio dos Sinos.

A otimização do uso de recursos hídricos, juntamente com aspectos energéticos já abordados, tratamento de águas e efluentes (VON SPERLING, 2003), gestão de resíduos sólidos e monitoramento de emissões atmosféricas são os principais indicadores considerados em abordagens sistêmicas de desenvolvimento sustentável, como diretrizes para políticas agrárias (VEIGA, 1998).

Na Figura 7 são apresentados os principais efluentes líquidos gerados.

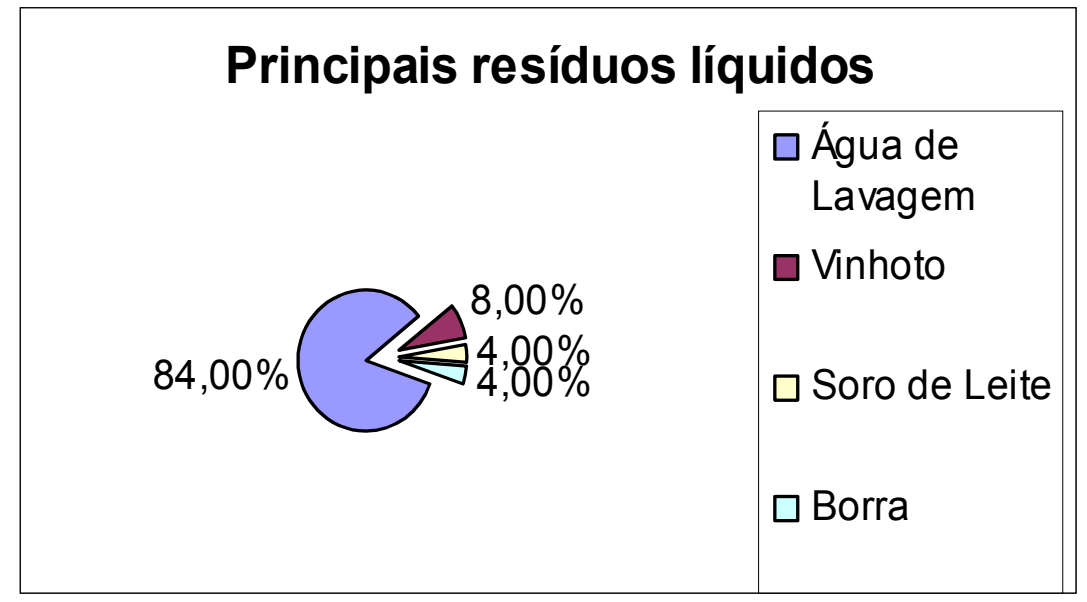

Figura 7: Principais tipos de efluentes gerados

Agroindústrias tendem a produzir algum tipo de efluente líquido, tratado na pesquisa como resíduo líquido. Estes efluentes quase sempre são gerados na lavagem das instalações industriais, mas também podem ser originados de atividades de destilação, decantação de vinho ou sobras na fabricação de queijos ou produtos de natureza Láctea em geral. 


\begin{tabular}{|c|c|c|}
\hline & $\begin{array}{c}\text { GEOAMBIENTE ON-LINE } \\
\text { Revista Eletrônica do Curso de Geografia - Campus Jata } \\
\text { Graduação e Pós-Graduação em Geografia } \\
\text { www2.jatai.ufg.br/ojs/index.php/geoambiente } \\
\text { Apoio: PRPPG/PROAPUPEC } \\
\text { | Jataí-GO | n.13 | jul-dez/2009 | }\end{array}$ & $\begin{array}{l}\text { LCEO } \\
\text { ISSN } 1679-9860\end{array}$ \\
\hline
\end{tabular}

A destinação final dos efluentes, tanto aqueles que recebem tratamento quanto os efluentes "in natura" são fossas e sumidouros, alimentos para animais, esgotos, esterqueira e processos de compostagem e processos de "landfarming" diversos em campo ou lavouras (DINIZ, 2002).

"Landfarming” é descrito como o uso de técnicas agrícolas, aeração mecânica e adubação química, para aumentar a atividade decompositora de microrganismos presentes no solo, para tratar resíduos in situ. A infiltração dos efluentes tratados pode ser considerado um processo químico que atua no sentido de fornecer nutrientes aumentando a atividade decompositora dos microrganismos presentes nos solos (DI BERNARDO e DANTAS, 2005).

$\mathrm{Na}$ adoção de soluções por "landfarming", os métodos biológicos empregados estão baseados no fato de que os microorganismos têm possibilidades praticamente ilimitadas para metabolizar compostos químicos (NAIME e FAGUNDES, 2005).

Tanto o solo como as águas subterrâneas contêm elevado número de microorganismos que, gradualmente, se vão adaptando às fontes de energia e carbono disponíveis, quer sejam açucares facilmente metabolizáveis, quer sejam compostos orgânicos complexos.

No tratamento biológico (FARIA e LERSCH, 2001), os microorganismos naturais presentes na matriz, são estimulados para uma degradação controlada dos contaminantes (dando às bactérias um ambiente propício com oxigênio, nutrientes, temperatura, $\mathrm{pH}$, humidade, misturas, etc).

As agroindústrias familiares pesquisadas tem estruturas muito deficientes, tanto para tratamento das águas que serão utilizadas, quanto para tratamento dos efluentes líquidos produzidos pelas águas servidas, aqui denominados resíduos líquidos.

O solo é um corpo vivo, de grande complexidade e muito dinâmico. Tem como componentes principais a fase sólida (matéria mineral e matéria orgânica), e a água e o ar na designada componente "não sólida". O solo é uma interface entre o ar e a água (entre a atmosfera e a hidrosfera), sendo imprescindível à produção de biomassa.

Mesmo o uso da terra para as atividades agrícolas de pecuária e lavoura tem tido como conseqüência elevados níveis de contaminação. De fato, aos usos referidos associam-se, geralmente, descargas acidentais ou voluntárias de poluentes no solo e águas, deposição não controlada de produtos que podem ser resíduos perigosos, lixeiras e/ou aterros sanitários não 


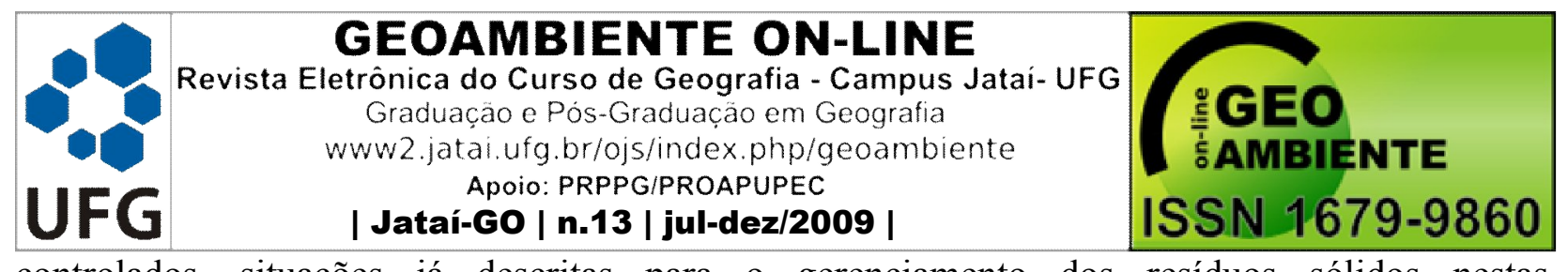

controlados, situações já descritas para o gerenciamento dos resíduos sólidos nestas agroindústrias e que produzem efeitos impactantes sobre as próprias populações humanas afetadas.

Assim, ao longo dos últimos anos, têm sido detectados numerosos casos de contaminação do solo em zonas rurais.

$\mathrm{Na}$ figura 8 é apresentada a situação encontrada nas agroindústrias familiares do Vale do Rio dos Sinos pesquisadas, quanto a existência de sistemas de tratamento de efluentes.

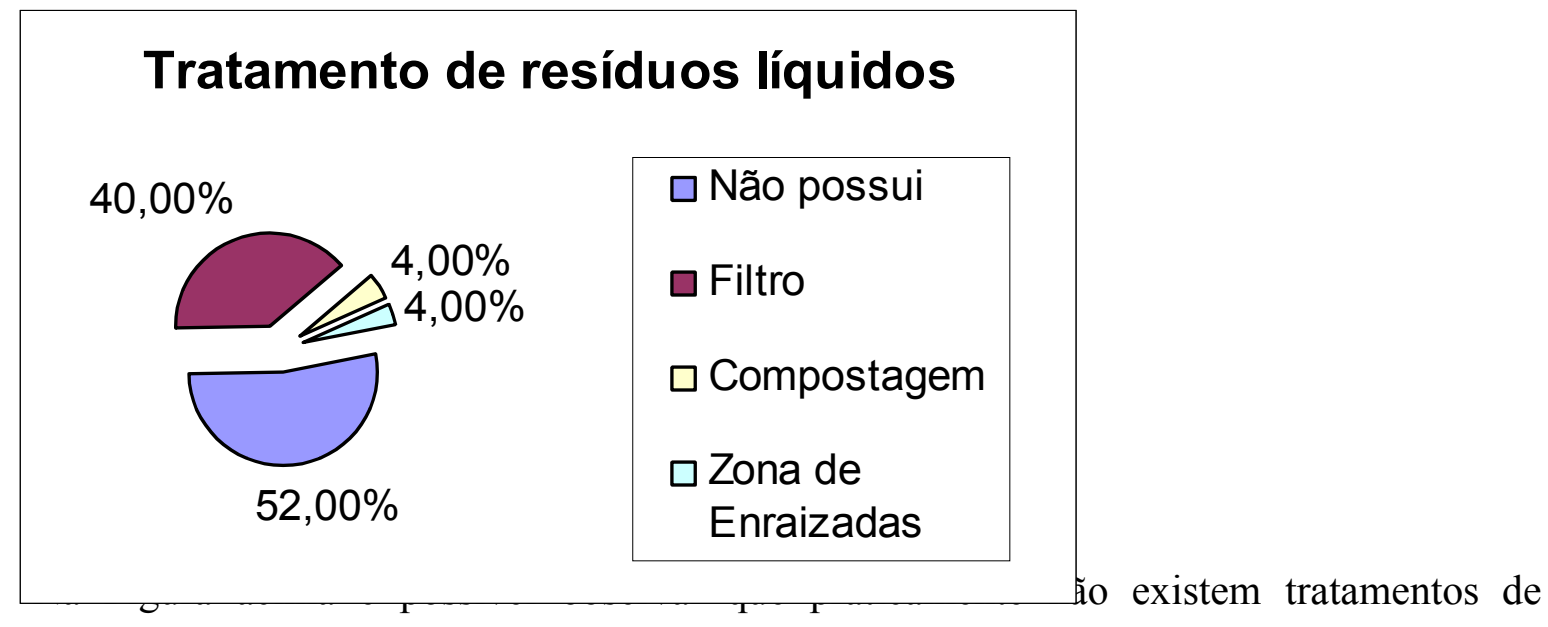

efluentes, pois filtros isolados não constituem estações de tratamento de efluentes eficientes (FARIA e MORANDI, 2002).

Foram realizadas análises microbiológicas da qualidade das águas em 25 agroindústrias. A Tabela 1 a seguir, apresenta os valores referentes à determinação de coliformes totais. Como não há indicativos na Portaria, a análise dos resultados toma por base o valor nulo, indicando assim os excedentes encontrados antes e depois do tratamento de água existente nos locais pesquisados.

$\mathrm{Na}$ maioria das agroindústrias familiares que tiveram águas coletadas para análise tanto antes quanto depois de processos de tratamento, observa-se a presença de volumes significativos de coliformes fecais, que acabam sendo introduzidos nos produtos coloniais produzidos pelas agroindústrias. A população tanto gosta de adquirir produtos de natureza colonial e desconhece a contaminação que pode ocorrer nos mesmos em virtude desta realidade, que ocorre muito mais por desconhecimento do que por ação deliberada de transgredir normas sanitárias. 


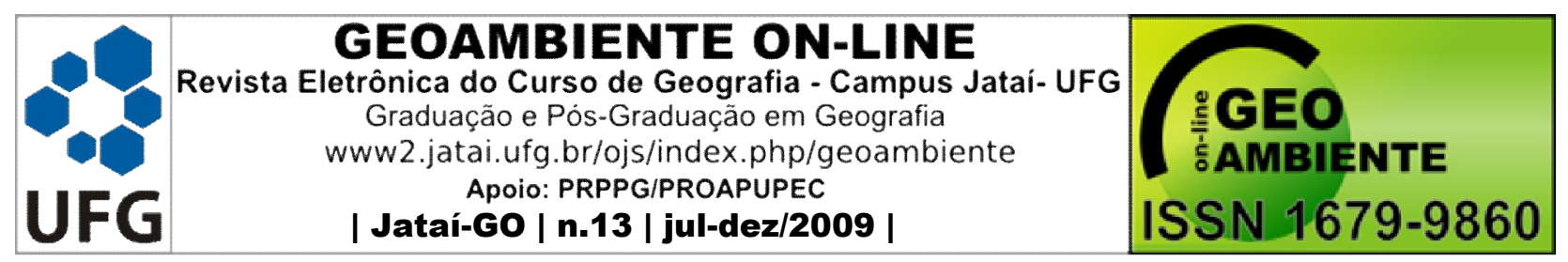

Tabela 1 - Parâmetros referentes à contaminação por coliformes totais (NMP/100mL)

\begin{tabular}{|c|c|c|c|c|c|}
\hline \multirow{2}{*}{$\begin{array}{l}\text { Parâmetro } \\
\text { (Coliformes Totais) }\end{array}$} & \multicolumn{2}{|c|}{ Valor observado } & \multirow{2}{*}{$\mathbf{V M P}^{1}$} & \multicolumn{2}{|c|}{ Valor excedido } \\
\hline & Antes $^{2}$ & Depois $^{3}$ & & Antes $^{2}$ & Depois $^{3}$ \\
\hline Agroindústria 1 & 520 & 1334 & Ausente & 520 & 1334 \\
\hline Agroindústria 2 & 9,8 & 388 & Ausente & 9,8 & 388 \\
\hline Agroindústria 3 & 2723 & 4569 & Ausente & 2723 & 4569 \\
\hline Agroindústria 4 & 122 & 2,0 & Ausente & 122 & 2,0 \\
\hline Agroindústria 5 & 201,4 & $---{ }^{4}$ & Ausente & 201,4 & $-y^{4}$ \\
\hline Agroindústria 6 & 2,0 & 43,2 & Ausente & 2,0 & 43,2 \\
\hline Agroindústria 7 & 1510 & $-{ }^{4}$ & Ausente & 1510 & $-{ }^{4}{ }^{4}$ \\
\hline Agroindústria 8 & 2723 & 4569 & Ausente & 2723 & 4569 \\
\hline Agroindústria 9 & 9,8 & 388 & Ausente & 9,8 & 388 \\
\hline Agroindústria 10 & $-{ }^{5}$ & 1553,1 & Ausente & $--^{5}$ & 1553,1 \\
\hline Agroindústria 11 & $---^{5}$ & 4,1 & Ausente & $---^{5}$ & 4,1 \\
\hline Agroindústria 12 & $---^{5}$ & 2419,6 & Ausente & $---^{5}$ & 2419,6 \\
\hline Agroindústria 13 & $----^{5}$ & Ausente & Ausente & $----^{5}$ & Ausente \\
\hline Agroindústria 14 & $---^{5}$ & Ausente & Ausente & $---^{5}$ & Ausente \\
\hline Agroindústria 15 & $----^{5}$ & 2419,6 & Ausente & $----^{5}$ & 2419,6 \\
\hline Agroindústria 16 & 2419,6 & $-4^{4}$ & Ausente & 2419,6 & $-4^{4}$ \\
\hline Agroindústria 17 & 60,2 & $-{ }^{4}{ }^{4}$ & Ausente & 60,2 & $-{ }^{4}{ }^{4}$ \\
\hline Agroindústria 18 & 114,5 & ----.4 & Ausente & 114,5 & ----.4 \\
\hline Agroindústria 19 & 49,5 & $-{ }^{4}{ }^{4}$ & Ausente & 49,5 & $-{ }^{4}{ }^{4}$ \\
\hline Agroindústria 20 & $>2419,6$ & $----{ }^{4}$ & Ausente & $>2419,6$ & $----{ }^{4}$ \\
\hline Agroindústria 21 & 3,1 & $-{ }^{4}{ }^{4}$ & Ausente & 3,1 & $-{ }^{---}{ }^{4}$ \\
\hline Agroindústria 22 & 920,8 & -----.4 & Ausente & 920,8 & -----4 \\
\hline Agroindústria 23 & 2419,6 & $--^{4}$ & Ausente & 2419,6 & $--^{4}$ \\
\hline Agroindústria 24 & $--{ }^{5}$ & 4,1 & Ausente & $--5^{5}$ & 4,1 \\
\hline Agroindústria 25 & Ausente & --.-. 4 & Ausente & Ausente & --.- 4 \\
\hline
\end{tabular}

${ }^{1}$ Segundo a Portaria MS 518/2004.

${ }^{2}$ Refere-se a água coletada na fonte de água de abastecimento da agroindústria.

${ }^{3}$ Refere-se á água coletada após o tratamento realizado pela agroindústria.

${ }^{4}$ Sem tratamento de água.

${ }^{5}$ Coleta de água indisponível.

A Portaria 518 determina que para as amostras procedentes de poços ou nascentes a ocorrência de coliformes totais deve ter sua origem investigada e devem ser tomadas providências imediatas de caráter corretivo e preventivo e então realizada nova análise. A seguir, a Tabela 2 apresenta os resultados referentes à contaminação por coliformes fecais. 


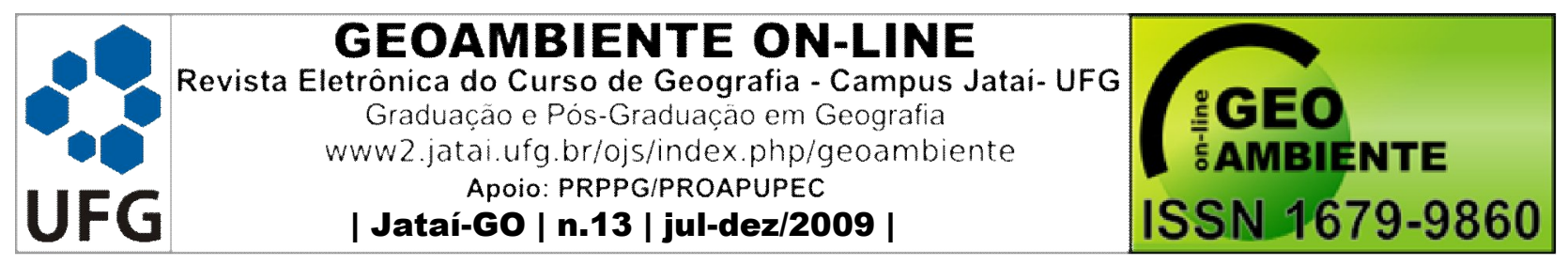

Tabela 2 - Parâmetros referentes à contaminação por coliformes fecais (NMP/100mL)

\begin{tabular}{|c|c|c|c|c|c|}
\hline \multirow{2}{*}{$\begin{array}{l}\text { Parâmetro } \\
\text { (Coliformes Fecais) }\end{array}$} & \multicolumn{2}{|c|}{ Valor observado } & \multirow{2}{*}{$\mathbf{V M P}^{1}$} & \multicolumn{2}{|c|}{ Valor excedido } \\
\hline & Antes $^{2}$ & Depois $^{3}$ & & Antes $^{2}$ & Depois $^{3}$ \\
\hline Agroindústria 1 & 20 & 86 & Ausente & 20 & 86 \\
\hline Agroindústria 2 & Ausente & Ausente & Ausente & Ausente & Ausente \\
\hline Agroindústria 3 & 13,5 & 48,7 & Ausente & 13,5 & 48,7 \\
\hline Agroindústria 4 & Ausente & Ausente & Ausente & Ausente & Ausente \\
\hline Agroindústria 5 & Ausente & $---{ }^{4}$ & Ausente & Ausente & $----^{4}$ \\
\hline Agroindústria 6 & Ausente & 2,0 & Ausente & Ausente & 2,0 \\
\hline Agroindústria 7 & 6,3 & $-\mathbf{- O}^{4}$ & Ausente & 6,3 & $-{ }^{4}$ \\
\hline Agroindústria 8 & 13,5 & 48,7 & Ausente & 13,5 & 48,7 \\
\hline Agroindústria 9 & Ausente & Ausente & Ausente & Ausente & Ausente \\
\hline Agroindústria 10 & $---^{5}$ & Ausente & Ausente & $---^{5}$ & Ausente \\
\hline Agroindústria 11 & $----^{5}$ & Ausente & Ausente & $----^{5}$ & Ausente \\
\hline Agroindústria 12 & $---^{5}$ & 65,0 & Ausente & $---^{5}$ & 65,0 \\
\hline Agroindústria 13 & $----^{5}$ & Ausente & Ausente & $----^{5}$ & Ausente \\
\hline Agroindústria 14 & $----^{5}$ & Ausente & Ausente & $--^{5}$ & Ausente \\
\hline Agroindústria 15 & $----^{5}$ & Ausente & Ausente & $----^{5}$ & Ausente \\
\hline Agroindústria 16 & Ausente & $----{ }^{4}$ & Ausente & Ausente & $---{ }^{4}$ \\
\hline Agroindústria 17 & Ausente & $-{ }^{4}$ & Ausente & Ausente & $-{ }_{---}^{4}$ \\
\hline Agroindústria 18 & 6,3 & $-{ }_{---}^{4}$ & Ausente & 6,3 & $-\mathrm{-}^{4}$ \\
\hline Agroindústria 19 & Ausente & $---^{4}$ & Ausente & Ausente & $-{ }^{-}{ }^{4}$ \\
\hline Agroindústria 20 & 12,1 & $-{ }^{---}{ }^{4}$ & Ausente & 12,1 & $-{ }^{---}{ }^{4}$ \\
\hline Agroindústria 21 & Ausente & $-{ }^{4}{ }^{4}$ & Ausente & Ausente & $-{ }^{-}{ }^{4}$ \\
\hline Agroindústria 22 & 7,5 & $----{ }^{4}$ & Ausente & 7,5 & $----{ }^{4}$ \\
\hline Agroindústria 23 & 131,4 & $---{ }^{4}$ & Ausente & 131,4 & $---{ }^{4}$ \\
\hline Agroindústria 24 & $----^{5}$ & Ausente & Ausente & $----^{5}$ & Ausente \\
\hline Agroindústria 25 & Ausente & $----{ }^{4}$ & Ausente & Ausente & $--^{4}{ }^{4}$ \\
\hline
\end{tabular}

\footnotetext{
Segundo a Portaria MS 518/2004.

${ }^{2}$ Refere-se a água coletada na fonte de água de abastecimento da agroindústria.

${ }^{3}$ Refere-se á água coletada após o tratamento realizado pela agroindústria.

${ }^{4}$ Sem tratamento de água.

${ }^{5}$ Coleta de água indisponível.
}

Assim como na tabela anterior é possível identificar a presença de coliformes fecais nas águas que são utilizadas na fabricação dos produtos e nas águas residuárias, tratadas ou não, que vão sofrer destinação final em corpos hídricos. Estes dados são um alerta para as autoridades responsáveis pela gestão sanitária do setor e ocorrem não por deliberada decisão de transgredir a legislação dos pequenos agroindustriais, mas por desconhecimento da situação ou de como resolver a questão.

Os coliformes fecais podem ser associados diretamente com as fezes, tanto de seres humanos como de animais que estejam na propriedade. No caso dos animais indica um manejo 


\begin{tabular}{|c|c|c|}
\hline UFG & $\begin{array}{c}\text { GEOAMBIENTE ON-LINE } \\
\text { Revista Eletrônica do Curso de Geografia - Campus Jatai- UFG } \\
\text { Graduacão e Pós-Graduação em Geografia } \\
\text { www2.jatai.ufg.br/ojs/index.php/geoambiente } \\
\text { Apoio: PRPPG/PROAPUPEC } \\
\text { | Jataí-GO | n.13 | jul-dez/2009 | }\end{array}$ & $\begin{array}{l}\text { ËGE } \\
\text { ISSN } 1679-9860\end{array}$ \\
\hline
\end{tabular}

deficiente dos mesmos, em locais que facilitam a infiltração e contaminação das águas superficiais e subterrâneas (CETESB, 2007, JORDÃO et al, 2005).

A presença de coliformes totais e fecais em grande parte das amostras de água sem tratamento mostra que se faz necessária uma orientação aos proprietários de agroindústrias da Região do Vale dos Sinos para que implantem um sistema de tratamento da água utilizada nos processos agroindustriais com o objetivo de que esta venha a se enquadrar no padrão de potabilidade exigido pela Portaria 518 do Ministério da Saúde (Brasil, 2004).

Observa-se que há casos em que o tratamento da água se mostrou ineficiente. A provável causa desta ineficiência é a falta de limpeza dos reservatórios de água já tratada ou a falha neste procedimento de higienização.

\section{4 - Conclusões}

Agroindústrias são atividades econômicas da indústria de transformação de produtos agropecuários. A agroindústria familiar é um segmento constituído por pequenos produtores rurais de alimentos de origem vegetal ou animal, além de pães, massas e produtos de baixa sofisticação tecnológica e ligados a cultura histórica e local. São grupos muito heterogêneos, que no estado do Rio Grande do Sul ocupam mais de $40 \%$ da área rural total e contribuem com quase $60 \%$ do valor de produção.

No Vale do Rio dos Sinos predominam os minifúndios e as pequenas e médias propriedades, sempre de origem familiar. As agroindústrias desenvolvidas nestas propriedades, carecem de cuidados com o manuseio, preparação, processamento e armazenamento das matérias primas beneficiadas por ausência de programas sistematizados de planejamento.

Ocorrem muitos impactos ambientais relevantes, tanto no tratamento de águas ou efluentes líquidos, quanto na gestão de resíduos sólidos e até mesmo no monitoramento de emissões atmosféricas.

A maior parte das agroindústrias catalogadas no Vale do Rio dos estão no município de Novo Hamburgo, maior município da região. A distribuição dos participantes por faixa etária é extremamente homogênea, mostrando que as agroindústrias são de grande importância para os adultos e indivíduos de terceira idade, exatamente as frações da população que encontram 


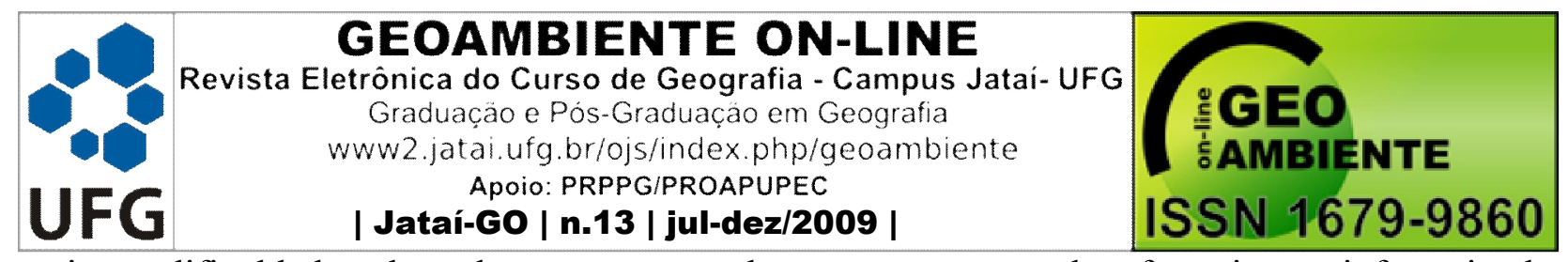

maiores dificuldades de colocação ou recolocação nos mercados formais ou informais de trabalho.

A principal fonte energética das agroindústrias é elétrica e trifásica, mostrando a importância da eletrificação rural na melhoria de qualidade de vida das populações.

As principais fontes de recursos hídricos são os aqüíferos subterrâneos através de poços tubulares profundos e as vertentes. Somente uma unidade pesquisada dependia do lençol freático superficial nos solos

O tratamento de água é inexistente. E a gestão dos resíduos sólidos produzidos é muito precária. A grande maioria das agroindústrias pesquisadas não possui qualquer tipo de tratamento para os resíduos sólidos que produz. As destinações de resíduos mais citadas foram a adubação e a alimentação de animais. A seguir vem a disposição inadequada a céu aberto e processos de compostagem, cama para suínos, fábrica de rações ou aterramento. Em um caso foi cita a queima simples dos resíduos e em outro a destinação para aterros sanitários públicos.

Da mesma forma, os tratamentos de efluentes líquidos são muito reduzidos, sendo limitados ao uso de filtros quando existem. Agroindústrias tendem a produzir algum tipo de efluente líquido, tratado na pesquisa como resíduo líquido. Estes efluentes quase sempre são gerados na lavagem das instalações industriais, mas podem ser oriundos de atividades de destilação, decantação de vinho ou sobras na fabricação de queijos ou produtos de natureza Láctea em geral.

A destinação final dos efluentes, tanto tratados, quanto "in natura" são fossas e sumidouros, alimentos para animais, esgotos, esterqueira e processos de compostagem e processos de "landfarming" diversos em campo ou lavouras.

A infiltração dos efluentes tratados pode ser considerado um processo químico que atua no sentido de fornecer nutrientes aumentando a atividade decompositora dos microrganismos presentes nos solos.

Nas análises microbiológicas a presença de coliformes totais e fecais em grande parte das amostras de água sem tratamento mostra que se faz necessária uma orientação aos proprietários de agroindústrias da Região do Vale dos Sinos para que implantem um sistema de tratamento da água utilizada nos processos agroindustriais com o objetivo de que esta venha a se enquadrar no padrão de potabilidade exigido pela Portaria 518 do Ministério da Saúde. 


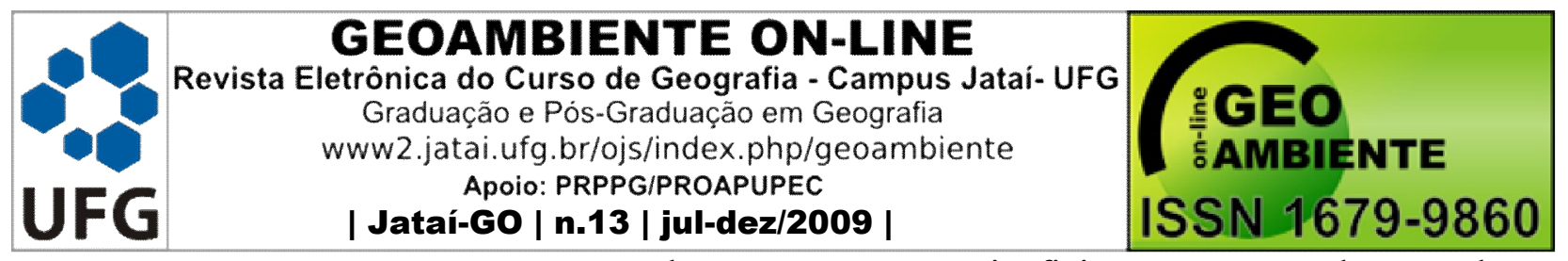

Nos casos em que o tratamento da água se mostrou ineficiente, a provável causa desta ineficiência é a falta de limpeza dos reservatórios de água já tratada ou a falha neste procedimento de higienização.

\section{Referências}

AMERICAN PUBLIC HEALTH ASSOCICIATION. Standard Methods for Examination of Water and Wastewater. $21^{\text {th }} \mathrm{Ed}, 2005$.

ANASTACI, A; URBINA, S. Fundamentos de testagem psicológica. Porto Alegre: Bookman, 2000.

AZEVEDO, N; NETTO, M. H. C. B. Manual de Saneamento de Cidades e Edificações. Ed. São Paulo Pini, 1991.

BANCO DO NORDESTE. Manual de Impactos Ambientais: orientações básicas sobre aspectos ambientais e atividades produtivas. Fortaleza: Banco do Nordeste, 1999. 297 p.

BARBIERI, J. C. Desenvolvimento e meio ambiente: As estratégias de mudanças da Agenda 21. $6^{\circ}$ Ed.Petrópolis,RJ: Vozes, 2004.

BARDIN, L. Analise de conteúdo. Lisboa, 70, 1977.

BRASIL - Ministério do Desenvolvimento Agrário: Manual do Entrevistador. Brasília: MDA, 2004. $88 \mathrm{p}$.

BRASIL. Lei Federal $n^{o} 6.938$ de 31 de agosto de 1981 - Dispõe sobre a Política Nacional do Meio Ambiente, seus fins e mecanismos de formulação e aplicação, e dá outras providências.

BRASIL. Ministério da Saúde. Secretaria de Vigilância em Saúde. Portaria $n^{\circ} 518$ de 25 de março de 2004. Brasília: Editora do Ministério da Saúde, 2005.

COMPANHIA DE TECNOLOGIA DE SANEAMENTO AMBIENTAL - CETESB. Variáveis de qualidade das águas. Disponível em: < http://www.cetesb.sp.gov.br/Agua/rios/variaveis.asp> Acesso em: 17 dez. 2007.

DI BERNARDO, L; DANTAS, A. B. Métodos e Técnicas de Tratamento de Água. 2. ed. São Paulo: RiMa, 2005.

DINIZ, E. D. P. Diagnóstico Ambiental da Bacia Hidrográfica do Arroio Cruze. Universidade Luterana do Brasil - Programa de Pós-Graduação em engenharia, energia, ambiente e materiais. Canoas - RS, 2002. 


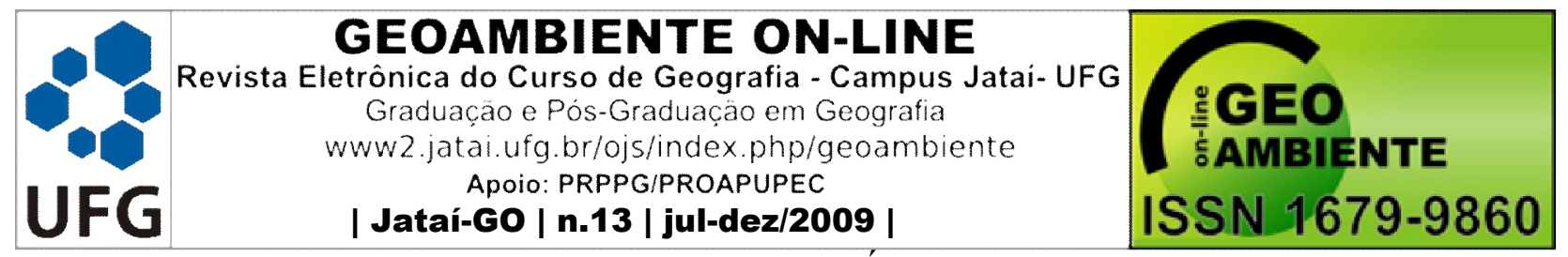

FARIA, C. M.; LERSCH, E. C. Monitoramento das Águas do Delta e Foz dos Rios Formadores do Guaíba. Pesquisa Ecos. Revista. Departamento municipal de Água e Esgotos. Porto Alegre. Ano 2. no 5 . Outubro/2001.

FARIA, C. M.; MORANDI, I. C.; A Difícil Recuperação de Arroios em Áreas Urbanas. Pesquisa Ecos. Revista. Departamento municipal de Água e Esgotos. Porto Alegre. Ano 3. no 6. Maio/2002.

FLICK, U. Uma Introdução à pesquisa qualitativa. Porto Alegre: Artmed, 2004.

GOEBERT, B. O consumidor e os focus groups. Net, São Paulo, 2003. Disponível em: http://www.hsmmanagement.com.br. Acesso em xx,mar, 2007.

JORDÃO, C. P.; PEREIRA, M. de G.; MATOS, A. T.; PEREIRA, J. L. Influence of Domestic and Industrial Waste Discharges on Water Quality at Minas Gerais State, Brazil. J. Braz. Chem. Soc, Vol. 16, No. 2, 241-250, 2005.

LAKATOS, E. M.; MARCONI, M. A. Metodologia cientifica. São Paulo: Atlas, 1999'. 177 p.

MAlHotra, N. Pesquisa de marketing: uma orientação aplicada. Porto Alegre: Bookman, 2001.

MARGENEU, H e BERGAMINI, D. O cientista. Rio de Janeiro: Jose Olympio, 1982.

NAIME, R.; FAGUNDES, R. S. Controle da Qualidade da água do Arroio Portão, RS. Instituto de Geociências, UFRGS, Pesquisa em Geociências, 32. Porto Alegre - Brasil, 2005.

NAIME, R. Diagnóstico ambiental e Sistemas de gestão ambiental. Novo Hamburgo. Feevale, $2.005,134 \mathrm{p}$

NASCIMENTO, C. A; NAIME, R CARVALHO, S. Busca por Água para Suprir as Necessidades Humanas e a Sustentabilidade do Aqüifero Subterrâneo em Loteamentos Irregulares na Cidade de Taquara - RS - Brasil. Instituto de Ciências Exatas e Tecnológica ICET. Centro Universitário FEEVALE. Tecnologia e Tendências. Novo Hamburgo - Brasil, junho de 2007.

RICHTER, C. A; NETTO, J. M. A. Tratamento de Água. Ed. São Paulo Edgar Blucher, 1995.

ROSSI, C. A. V; HOR MEYLL, L. F. Explorando novas trilhas na pesquisa do consumidor. In:

ENAMPAD, 25, 2001, Campinas (SP). 


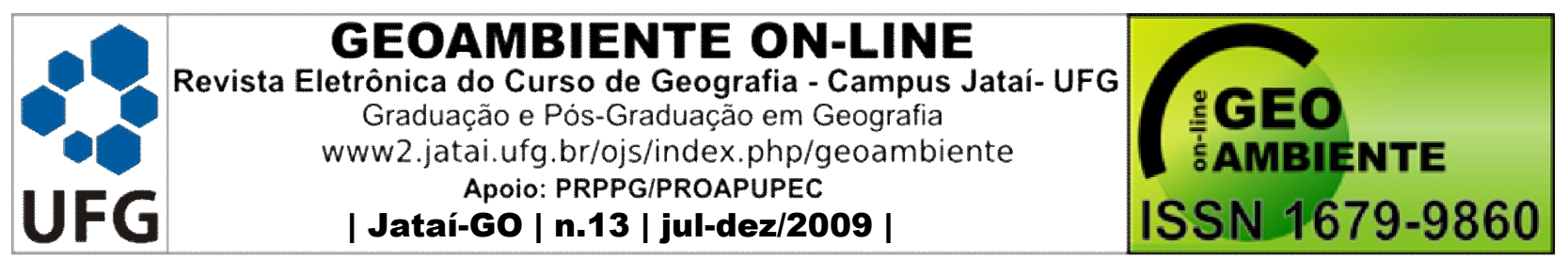

SANTOS, R. C; CERQUEIRA, V. Sacramento. Manual para a aplicação das boas práticas agropecuárias e de fabricação na agroindústria. Porto Alegre: EMATER/RS-ASCAR, 2007. $130 \mathrm{p}$.

TRIVIÑOS, A.N.S. Introdução à pesquisa em ciências sociais: a pesquisa qualitativa em educação. São Paulo: Atlas, 1992.

TUCCI, C.E.M. "Hidrologia: Ciência e Aplicação". Porto Alegre. Editora da Universidade: ABRH:EDUSP, 1993

VEIGA, J.E.V. "Diretrizes para uma nova política agrária. Seminário sobre reforma agrária e desenvolvimento sustentável”. Fortaleza. 1998.

VON SPERLING, M. Introdução à qualidade das águas e ao tratamento de esgotos. 2. ed. rev. Belo Horizonte: DESA - UFMG, 2003.

ZALTMAN, G. Afinal, o que os clientes querem? O que os consumidores não contam e os concorrentes não sabem. São Paulo: Campus, 2003.

\section{6 - Agradecimentos}

Agradecimentos a FAPERGS que financiou este trabalho através do processo 0518950; agradecimentos as unidades da EMATER, a FAMURS (Federação de Agricultura dos Municípios do Rio Grande do Sul) e a FETAG (Federação dos Trabalhadores na Agricultura, secção RS) pela parceria no projeto e ao Centro Universitário Feevale, pelas excelentes condições ofertadas ao trabalho de seus pesquisadores no Mestrado em Qualidade Ambiental. 